\title{
RED BLOOD CELLS PARAMETERS IN PATIENTS WITH ACUTE SCHIZOPHRENIA, UNIPOLAR DEPRESSION AND BIPOLAR DISORDER
}

\author{
Adam Wysokiński \& Ewa Szczepocka \\ Department of Old Age Psychiatry and Psychotic Disorders, Medical University of Lodz, Lodz, Poland
}

received: 22.9.2016;

revised: 7.8.2018;

accepted: 5.9.2018

\begin{abstract}
SUMMARY
Background: There are no studies comparing red blood cell parameters between patients with schizophrenia, bipolar disorder and unipolar depression. The aim of this study was to compare differences in erythrocyte parameters (red blood cell count (RBC), hematocrit (HCT), hemoglobin (HGB), mean corpuscular volume (MCV), mean corpuscular hemoglobin (MCH), mean corpuscular hemoglobin concentration (MCHC), and red blood cell distribution width (RDW)) in patients with schizophrenia (SHZ), unipolar depression (UD) and bipolar disorder (BIP): bipolar depression (BD) and mania (BM).

Subjects and methods: This was a retrospective, cross-sectional, naturalistic study of 2381 patients (SHZ $n=1244$; UD $n=794$; $B I P n=343, B D n=259, B M n=84$ ).

Results: There was significant difference for all red cell parameters between study groups $(p<0.001)$. Age and sex may affect various erythrocyte parameters.

Conclusion: There are differences in erythrocyte parameters between schizophrenia, unipolar depression and bipolar disorder. Compared with schizophrenia, significantly higher percentage of patients with affective disorders has anemia or abnormal erythrocyte parameters. Positive correlations between age and $M C V$ and RDW and negative correlation between other parameters and age were found in all study groups.
\end{abstract}

Key words: anemia - bipolar disorder - depression - red blood cells - schizophrenia

\section{INTRODUCTION}

Red blood cells, also called erythrocytes, are the most common type of blood cell (George-Gay \& Parker 2003). Their most important function is the transport of oxygen. Number of erythrocytes is usually termed as the red blood cell count (RBC). A typical human erythrocyte has a disk diameter of approximately 6.2-8.2 $\mu \mathrm{m}$. The cytoplasm of erythrocytes is rich in hemoglobin, an iron-containing biomolecule that can bind oxygen and is responsible for their red color. They lack a cell nucleus and most organelles, in order to accommodate maximum space for hemoglobin. Approximately 2.4 million new erythrocytes are produced per second in human adults. The cells develop in the bone marrow in the process called erythropoiesis and circulate for about 100-20 days in the body before their components are recycled by macrophages.

Hemoglobin (HGB) is the most important component of erythrocytes. It is composed of a protein called heme, which carries oxygen from the lungs to peripheral tissues. HGB is an excellent indicator of iron status and blood oxygenation (Ellman \& Vinogradov et al. 2012). Hematocrit (HCT) is the volume percentage of red blood cells in blood. Mean corpuscular volume (MCV) is the average size of a red blood cell and is calculated by dividing HCT by RBC. Mean corpuscular hemoglobin $(\mathrm{MCH})$ is the average amount of hemoglobin per red blood cell and is calculated by dividing HGB by RBC. Mean corpuscular hemoglobin concentration
(MCHC) is the average concentration of hemoglobin per unit volume of red blood cells and is calculated by dividing HGB by HCT. Red blood cell distribution width (RDW) is a measure of the range of variation of red blood cell volume that is reported as part of a standard complete blood count. Certain disorders may cause a significant variation in cell size and higher RDW values indicate greater variation in size.

Schizophrenia, bipolar disorder and unipolar depression are severe mental disorders with complex etiology and pathophysiology that are far from being established. These diseases affect millions of people worldwide and are associated with great human and economic costs (stigma, limited activity, decreased life expectancy and raised healthcare costs). The relation between red blood cells structure and mental disorders has long been recognized. Studies show that physiological properties of erythrocytes may be abnormal in patients with schizophrenia (Riazantseva \& Novitskii 2002). The relationship between major depression and decreased red blood cell parameters has been previously stated by several studies (Maes \& Van de Vyvere et al. 1996, Alves de Rezende \& Coelho et al. 2009).

There are no studies comparing red blood cell parameters between patients with schizophrenia, bipolar disorder and unipolar depression. Therefore, the aim of this study was to determine and compare differences in RBC, MCV, MCHC, HGB, HCT and RDW between patients with schizophrenia, unipolar depression and bipolar disorder. 


\section{SUBJECTS AND METHODS}

This was a naturalistic, retrospective, cross-sectional study. Our psychiatry clinical hospital database was screened for complete blood count examinations. Data from years 2011-2016 was collected. All data available for that time period was analyzed. Only the first entry for each patient from inpatient care units was used for analysis. Usually the first blood tests are done next day after admission to our units. Thus, we have assumed that most patients that we included in the study were in acute phase of their disorder. We focused on patients with schizophrenia (all subtypes), bipolar disorder and unipolar depression.

Results for adult Caucasian patients were included in the study. Patients were grouped under diagnostic criteria as schizophrenia (F20 according to ICD-10, 295 according to DSM-IV), unipolar depression (F31 and F32 according to ICD-10, 296.2 and 296.3 according to DSM-IV), bipolar disorder (F30 and F31 according to ICD-10, 296. $(0,4,6)$ according to DSM-IV), which included: bipolar depression (F31.3-F31.5 according to ICD-10, 296.6 according to DSM-IV) and bipolar mania (F30 and F31.0-F31.2 according to ICD-10, 296.0 and 296.4 according to DSM-IV). In our unit diagnosis is based on the ICD-10 criteria, DSM-IV codes were given as reference. As a general rule, most patients with coexisting (or present within 3-4 weeks prior the blood collection) severe somatic diseases (e.g. acute autoimmune and inflammatory diseases, renal failure, cancer or other), which may significantly affect various blood parameters, are referred to other specialist units prior to admission to our unit. Thus, we assume that observed results are mostly related to psychiatric conditions. The study protocol was approved by the Ethical Committee of the Medical University of Lodz, Poland.

Table 1. Complete blood count - reference ranges

\begin{tabular}{lc}
\hline Parameter & Reference range \\
\hline RBC & $4.0-5.4 \times 10^{6} / \mathrm{mm}^{3}$ \\
HCT & $40.0-54.0 \%$ \\
HGB - women & $12.0 \mathrm{~g} / \mathrm{dL}$ \\
$\mathrm{HGB}-$ men & $13.0 \mathrm{~g} / \mathrm{dL}$ \\
$\mathrm{MCV}$ & $80.0-100.0 \mu \mathrm{m}^{3}$ \\
$\mathrm{MCH}$ & $27.0-32.0 \mathrm{pg}$ \\
$\mathrm{MCHC}$ & $32.0-37.0 \mathrm{~g} / \mathrm{dL}$ \\
$\mathrm{RDW}$ & $11.6-14.4 \%$ \\
\hline $\mathrm{RBC}=$ red blood cell count; & $\mathrm{HCT}=$ hematocrit; \\
$\mathrm{HGB}=$ hemoglobin; $\mathrm{MCV}=$ mean corpuscular volume; \\
$\mathrm{MCH}=$ mean corpuscular hemoglobin; \\
$\mathrm{MCHC}=$ mean corpuscular hemoglobin concentration; \\
RDW = red blood cell distribution width.
\end{tabular}

Blood samples were drawn for all patients between 8 and 9 a.m. after 12 hours overnight fast. Immediately after collecting blood samples, complete blood count was determined using Sysmex XS-1000i TM Automated Hematology Analyzer (Sysmex, USA). The follo- wing red blood cell parameters were measured: RBC (expressed in $\times 10^{6} / \mathrm{mm}^{3}$ ), MCV (expressed in $\mathrm{fL}$ ), $\mathrm{MCH}$ (expressed in pg), MCHC (expressed in $\mathrm{g} / \mathrm{dL}$ ), HGB (expressed in $\mathrm{g} / \mathrm{dL}$ ), HCT (expressed in \%) and RDW (expressed in \%). Table 1 shows our laboratory reference ranges used in the analysis.

Statistical procedures were performed with STATA 14.1 (StataCorp, USA). Simple descriptive statistics (mean \pm standard deviation) were generated for continuous variables. For discrete variables number of patients and percentages are given. Normality of distribution was tested with Shapiro-Wilk test. Variables that did not follow normal distribution, even after transformation, were analyzed using Kruskal-Wallis test or Mann-Whitney two-sample rank-sum test, otherwise one-way ANOVA and t-test were used. The difference between proportions was analyzed with the chi-square test. Associations were tested by Spearman's correlation coefficient. Odds ratios (OR) with $95 \%$ confidence intervals (CI) were calculated using adjusted logistic regression. The level of significance was set at $\mathrm{p}<0.05$.

The study has been approved by the appropriate ethics. The authors assert that all procedures contributing to this work comply with the ethical standards of the relevant national and institutional committees on human experimentation and with the Helsinki Declaration of 1975 , as revised in 2008 .

\section{RESULTS}

In the study group of 2381 patients included in the analysis there were $60.0 \%$ women $(\mathrm{n}=1429)$. The proportion of women in the schizophrenia group $(n=1244)$ was $46.9 \%(n=583), 76.3 \%(n=606)$ in the unipolar depression group $(\mathrm{n}=794), 70.0 \%(\mathrm{n}=240)$ in the bipolar disorder group $(\mathrm{n}=343), 72.2 \%(\mathrm{n}=187)$ in the bipolar depression group $(\mathrm{n}=259), 63.1 \%(\mathrm{n}=53)$ in the bipolar mania $(\mathrm{n}=84)$, see Figure 1.

The difference between the groups in the proportion of women was significant $\left(\chi^{2}=194.0, p<0.001\right)$, with the lowest proportion of women in the schizophrenia group. In the schizophrenia group there were 4 patients with hebephrenic subtype, 5 with residual schizophrenia and 2 with simple-type schizophrenia. These subgroups were too small to include them into separate analysis and therefore we decided to combine all patients with

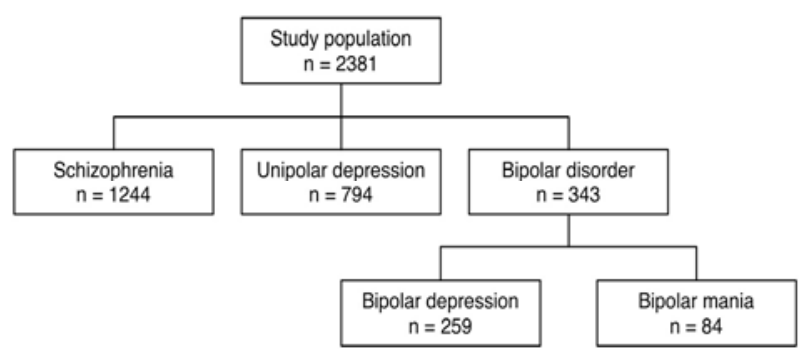

Figure 1a. Distribution of subjects and distribution of age (in years) in the study groups 


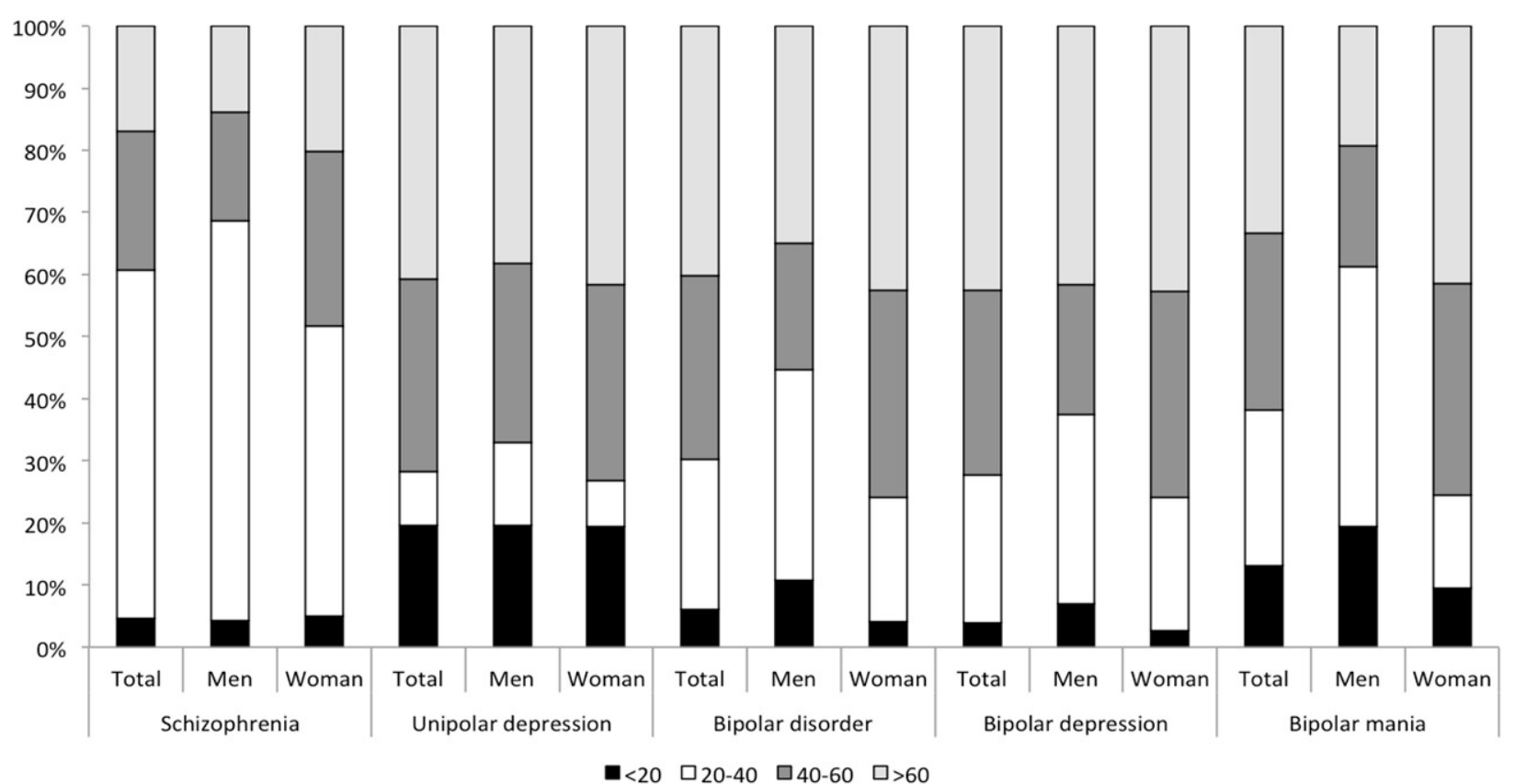

Figure 1b. Distribution of subjects and distribution of age (in years) in the study groups

Table 2. Age distribution in the study sample

\begin{tabular}{|c|c|c|c|c|c|c|}
\hline \multirow{2}{*}{ Group } & & \multicolumn{4}{|c|}{ Age category } & \multirow{2}{*}{ Total } \\
\hline & & $<20$ & $20-40$ & $40-60$ & $>60$ & \\
\hline \multirow[t]{3}{*}{ Schizophrenia } & Men & 28 & 426 & 115 & 92 & $661(53.1)$ \\
\hline & Women & 29 & 272 & 164 & 118 & $583(46.9)$ \\
\hline & Total & 57 & 698 & 279 & 210 & 1244 \\
\hline \multirow[t]{3}{*}{ Unipolar depression } & Men & 37 & 25 & 54 & 72 & $188(23.7)$ \\
\hline & Women & 118 & 45 & 191 & 252 & $606(76.3)$ \\
\hline & Total & 155 & 70 & 245 & 324 & 794 \\
\hline \multirow[t]{3}{*}{ Bipolar disorder } & Men & 11 & 35 & 21 & 36 & $103(30.0)$ \\
\hline & Women & 10 & 48 & 80 & 102 & $240(70.0)$ \\
\hline & Total & 21 & 83 & 101 & 138 & 343 \\
\hline \multirow{3}{*}{ Bipolar depression } & Men & 5 & 22 & 15 & 30 & $72(27.8)$ \\
\hline & Women & 5 & 40 & 62 & 80 & $187(72.2)$ \\
\hline & Total & 10 & 62 & 77 & 110 & 259 \\
\hline \multirow[t]{3}{*}{ Bipolar mania } & Men & 6 & 13 & 6 & 6 & $31(36.9)$ \\
\hline & Women & 5 & 8 & 18 & 22 & $53(63.1)$ \\
\hline & Total & 11 & 21 & 24 & 28 & 84 \\
\hline
\end{tabular}

Results given as $\mathrm{n}$ or $\mathrm{n}(\%)$

schizophrenia into one group. The age of the study group was $45.6 \pm 19.6$ years. Mean age in the subgroups was: schizophrenia 40.3 \pm 16.2 , unipolar depression $51.4 \pm 22.3$, bipolar depression $52.6 \pm 18.2$, bipolar mania 46.0 \pm 19.2 . One-way ANOVA showed that there were significant age differences between the groups $(\mathrm{F}=69.77$, $\mathrm{p}<0.001)$. Post hoc comparisons using the Bonferroni test showed that patients with unipolar- and bipolar depression groups were significantly older $(\mathrm{p}<0.001$ for both groups). Age distribution in the study sample is shown in Figure 1 and Table 2.

Mean values of hematological parameters are given in Table 3, with significant $(\mathrm{p}<0.001)$ inter-group differences for all parameters. For the whole study group there was a significant differences between men and women for RBC ( $4.8 \pm 0.5$ vs. $4.4 \pm 0.4, z=-22.2, p<0.001)$,
HCT ( $42.7 \pm 3.8$ vs. $38.8 \pm 3.4, \mathrm{z}=-23.6, \mathrm{p}<0.001)$, HGB (14.7 \pm 1.4 vs. $13.1 \pm 1.2, \mathrm{z}=-25.6, \mathrm{p}<0.001), \mathrm{MCV}(89.0 \pm 4.3$ vs. $89.2 \pm 5.0, \mathrm{z}=2.7, \mathrm{p}=0.006), \mathrm{MCH}(30.6 \pm 1.5$ vs. $30.2 \pm 1.9, \quad \mathrm{z}=-4.2, \quad \mathrm{p}<0.001), \quad \mathrm{MCHC} \quad(34.4 \pm 0.9 \quad$ vs. $33.8 \pm 0.9, \mathrm{z}=-13.5, \mathrm{p}<0.001)$ and RDW $(13.2 \pm 0.8$ vs. $13.4 \pm 1.3, \mathrm{z}=3.8, \mathrm{p}<0.001)$.

Table 4 shows distribution of low, normal and high ranges of $\mathrm{RBC}, \mathrm{HCT}, \mathrm{HGB}, \mathrm{MCV}, \mathrm{MCH}, \mathrm{MCHC}$ and RDW in study groups. Patients with bipolar depression had the highest percentage of abnormal results for RBC (19.7\%) and for MCH (22.2\%). Patients with unipolar depression had the highest percentage of abnormal results for HCT (56.5\%), MCV (5.7\%) and RDW (14.8\%). There were no significant inter-group differences for HGB and MCHC. Apart from MCV and $\mathrm{MCH}$, patients with RBC, HGB, HCT, MCHC below normal range were 
Table 3. Mean hematological parameters in diagnostic groups

\begin{tabular}{lcccccc}
\hline Parameter & Schizophrenia & $\begin{array}{c}\text { Unipolar } \\
\text { depression }\end{array}$ & $\begin{array}{c}\text { Diagnosis } \\
\text { Bipolar } \\
\text { disorder }\end{array}$ & $\begin{array}{c}\text { Bipolar } \\
\text { depression }\end{array}$ & $\begin{array}{c}\text { Bipolar } \\
\text { mania }\end{array}$ & $\mathrm{p}$ \\
\hline RBC & $4.6 \pm 0.5$ & $4.4 \pm 0.5$ & $4.4 \pm 0.5$ & $4.4 \pm 0.5$ & $4.5 \pm 0.5$ & $\mathrm{H}=79.1$ \\
HCT & $(4.6)$ & $(4.5)$ & $(4.4)$ & $(4.4)$ & $(4.4)$ & $\mathrm{p}<0.001$ \\
& $40.9 \pm 4.0$ & $39.5 \pm 4.0$ & $39.9 \pm 3.8$ & $39.8 \pm 3.7$ & $40.0 \pm 4.1$ & $\mathrm{H}=68.8$ \\
HGB & $(41.0)$ & $(39.5)$ & $(39.9)$ & $(40.1)$ & $(39.6)$ & $\mathrm{p}<0.001$ \\
& $14.0 \pm 1.4$ & $13.4 \pm 1.4$ & $13.5 \pm 1.3$ & $13.5 \pm 1.3$ & $13.5 \pm 1.4$ & $\mathrm{H}=89.4$ \\
MCV & $(14.0)$ & $(13.4)$ & $(13.4)$ & $(13.5)$ & $(13.3)$ & $\mathrm{p}<0.001$ \\
& $88.9 \pm 4.6$ & $88.9 \pm 5.0$ & $90.5 \pm 4.1$ & $90.7 \pm 4.2$ & $89.7 \pm 3.8$ & $\mathrm{H}=37.0$ \\
MCH & $(88.8)$ & $(89.4)$ & $(90.0)$ & $(90.5)$ & $(89.5)$ & $\mathrm{p}<0.001$ \\
MCHC & $30.3 \pm 1.7$ & $30.1 \pm 1.9$ & $30.7 \pm 1.5$ & $30.9 \pm 1.5$ & $30.4 \pm 1.3$ & $\mathrm{H}=33.1$ \\
& $(30.3)$ & $(30.3)$ & $(30.6)$ & $(30.8)$ & $(30.4)$ & $\mathrm{p}<0.001$ \\
RDW & $34.1 \pm 0.9$ & $33.8 \pm 0.9$ & $34.0 \pm 0.9$ & $34.0 \pm 0.9$ & $33.9 \pm 0.8$ & $\mathrm{H}=39.5$ \\
& $(34.2)$ & $(33.8)$ & $(33.9)$ & $(34.0)$ & $(34.0)$ & $\mathrm{p}<0.001$ \\
\hline RBC & $13.2 \pm 0.9$ & $13.4 \pm 1.3$ & $13.3 \pm 1.0$ & $13.3 \pm 1.0$ & $13.3 \pm 1.1$ & $\mathrm{H}=16.9$
\end{tabular}

$\mathrm{RBC}=$ red blood cell count; $\mathrm{HCT}=$ hematocrit; $\mathrm{HGB}=$ hemoglobin; $\mathrm{MCV}=$ mean corpuscular volume;

$\mathrm{MCH}=$ mean corpuscular hemoglobin; $\mathrm{MCHC}=$ mean corpuscular hemoglobin concentration; $\mathrm{RDW}=$ red blood cell distribution width. Results given as mean \pm standard deviation (median); H - Kruskal-Wallis test

significantly older $(\mathrm{p}<0.01$ for all variables), while patients with RDW below normal range were significantly younger $(\mathrm{p}=0.02)$. Apart from HCT and MCHC, patients with $\mathrm{MCV}, \mathrm{MCH}$ and $\mathrm{RDW}$ above normal range were significantly older ( $\mathrm{p}<0.001$ for all variables), while patients with $\mathrm{RBC}$ above normal range were significantly younger $(\mathrm{p}=<0.001)$.

Table 5 shows the distribution of anemia and its subtypes (normocytic, microcytic or macrocytic) by the study groups. Anemia was defined as a decrease in the amount of red blood cells $\left(\mathrm{RBC}<4.0 \times 10^{6} / \mathrm{mm}^{3}\right)$ or hemoglobin $(\mathrm{HGB}<12.0 \mathrm{~g} / \mathrm{dL}$ for women and $<13.0$ $\mathrm{g} / \mathrm{dL}$ for men) in the blood (Beutler \& Waalen 2006). Macrocytic anemia was defined as anemia with MCV $>100 \mu \mathrm{m} 3$, normocytic anemia was defined as anemia with MCV between 80 and $100 \mu \mathrm{m}^{3}$, while microcytic anemia was defined as anemia with $\mathrm{MCV}<80 \mu \mathrm{m}^{3}$. Anemia subtypes differed significantly between the study groups $\left(\chi^{2}=24.5, p=0.004\right.$ by overall Chi-square test), with the lowest frequency among patients with schizophrenia and the highest frequencies in patients with unipolar- or bipolar affective disorders. Also, patients with unipolar depression had the highest frequency of microcytic anemia $(2.6 \%)$, which was not found in any of the bipolar disorder patients.

Table 6 shows correlations between hematological parameters and age in diagnostic groups. Also, we tested several regression models for red blood cells parameters and calculated odds ratios for hematological parameters being below or above normal values. All models were adjusted for sex and age, with the schizophrenia group as the reference. For RBC we found that sex and age were statistically significant in the model $\left(\mathrm{p}<0.001, \mathrm{R}^{2}=0.28\right)$, with male sex associated with increased (regression coefficients $\beta=0.39$ ) and age associated with decreased $(\beta=-0.01)$ value. For HCT sex and age were statistically significant in the model $\left(\mathrm{p}<0.001, \mathrm{R}^{2}=0.25\right)$, with male sex associated with increased $(\beta=3.54)$ and age associated with decreased $(\beta=-0.04)$ value. For HGB sex and age were statistically significant in the model $\left(\mathrm{p}<0.001, \mathrm{R}^{2}=0.31\right)$, with male sex associated with increased $(\beta=1.41)$ and age associated with decreased $(\beta=-0.02)$ value. For MCV age and diagnosis of bipolar depression were statistically significant in the model $\left(\mathrm{p}<0.001\right.$, respectively; $\left.\mathrm{R}^{2}=0.07\right)$, with bipolar depression and age associated with increased value ( $\beta=1.18$ and 0.06 , respectively). For $\mathrm{MCH}$ sex, age and diagnosis of bipolar depression were statistically significant in the model $\left(\mathrm{p}<0.001, \mathrm{R}^{2}=0.05\right)$, with age, male sex and bipolar depression associated with increased value $(\beta=0.01,0.52$ and 0.50 , respectively). For MCHC sex and age were statistically significant in the model $\left(\mathrm{p}<0.001, \mathrm{R}^{2}=0.10\right)$, with male sex associated with increased $(\beta=0.50)$ and age associated with decreased $(\beta=-0.01)$ value. For RDW sex, age and diagnosis of unipolar depression were statistically significant in the model $(\mathrm{p}=0.004, \mathrm{p}<0.001$ and $\mathrm{p}=0.02$, respectively; $\left.\mathrm{R}^{2}=0.04\right)$, with age and bipolar depression associated with increased value $(\beta=0.01$ and 0.12 , respectively) and male sex associated with decreased value $(\beta=-0.14)$.

For RBC below normal value male sex was associated with decreased risk $(\mathrm{OR}=0.38$ (95\% CI: 0.28-0.54), $\mathrm{p}<0.001)$ and age was associated with increased risk $(\mathrm{OR}=1.04$ (95\% CI: 1.03-1.05), $\mathrm{p}<0.001)$. Conversely, for $\mathrm{RBC}$ above normal value male sex was associated with increased risk (OR=18.98 (95\% CI: 8.57-42.04), $\mathrm{p}<0.001)$ and age was associated with decreased risk $(\mathrm{OR}=0.94$ (95\% CI: 0.94-0.97), $\mathrm{p}<0.001)$. For HCT below normal value male sex was associated with decreased risk $(\mathrm{OR}=0.17$ (95\% CI: 0.14-0.20), $\mathrm{p}<0.001)$ and age was associated with increased risk $(\mathrm{OR}=1.02(95 \%$ CI: 1.01-1.02), $\mathrm{p}<0.001)$. For HGB below normal value diagnosis of bipolar depression was associated with decreased risk (OR=0.53 (95\% CI: 0.34-0.83), $\mathrm{p}=0.006)$ 
Table 4. Distribution of low, normal and high ranges of hematological parameters in diagnostic groups

\begin{tabular}{|c|c|c|c|c|}
\hline & \multicolumn{3}{|c|}{$\mathrm{RBC}$} & \multirow{2}{*}{$\mathrm{p}$} \\
\hline & $<4.0$ & $4.0-5.4$ & $>5.4$ & \\
\hline Schizophrenia & $118(9.5)$ & $1061(85.3)$ & $65(5.2)$ & $\chi^{2}=37.8$ \\
\hline Unipolar depression & $127(16.0)$ & $642(80.9)$ & $25(3.1)$ & $\mathrm{p}<0.001$ \\
\hline Bipolar disorder & $62(18.1)$ & $276(80.5)$ & $5(1.5)$ & \\
\hline Bipolar depression & $48(18.5)$ & $208(80.3)$ & $3(1.2)$ & \\
\hline \multirow[t]{3}{*}{ Bipolar mania } & $14(16.7)$ & $68(80.9)$ & $2(2.4)$ & \\
\hline & & HCT & & \\
\hline & $<40.0$ & $40.0-54.0$ & $>54.0$ & \\
\hline Schizophrenia & $486(39.1)$ & $758(60.9)$ & 0 & $\chi^{2}=56.1$ \\
\hline Unipolar depression & $440(55.4)$ & $353(44.5)$ & $1(1.1)$ & $\mathrm{p}<0.001$ \\
\hline Bipolar disorder & $167(48.7)$ & $176(51.3)$ & 0 & \\
\hline Bipolar depression & $124(47.9)$ & $135(52.1)$ & 0 & \\
\hline \multirow[t]{3}{*}{ Bipolar mania } & $43(51.2)$ & $41(48.8)$ & 0 & \\
\hline & \multicolumn{3}{|c|}{ HGB } & \\
\hline & $\begin{array}{r}<12.0 \text { for } \\
<13.0 \mathrm{f} \\
\end{array}$ & & $\begin{array}{c}\geq 12.0 \text { for women } \\
\geq 13.0 \text { for men }\end{array}$ & \\
\hline Schizophrenia & 156( & & $1088(87.5)$ & $\chi^{2}=4.7$ \\
\hline Unipolar depression & 121( & & $673(84.8)$ & $\mathrm{p}=0.20$ \\
\hline Bipolar disorder & $40(1$ & & $303(88.3)$ & \\
\hline Bipolar depression & $28(1$ & & $231(89.2)$ & \\
\hline Bipolar mania & $12(1$ & & $72(85.7)$ & \\
\hline
\end{tabular}

\begin{tabular}{|c|c|c|c|c|}
\hline & & $\mathrm{MCV}$ & & \\
\hline & $<80.0$ & $80.0-100.0$ & $>100.0$ & \\
\hline Schizophrenia & $31(2.5)$ & $1198(96.3)$ & $15(1.2)$ & $\chi^{2}=19.2$ \\
\hline Unipolar depression & $35(4.4)$ & $749(94.3)$ & $10(1.3)$ & $\mathrm{p}=0.004$ \\
\hline Bipolar disorder & 0 & $340(99.1)$ & $3(0.9)$ & \\
\hline Bipolar depression & 0 & $256(98.8)$ & $3(1.2)$ & \\
\hline Bipolar mania & 0 & $84(100)$ & 0 & \\
\hline & & $\mathrm{MCH}$ & & \\
\hline & $<27.0$ & $27.0-32.0$ & $>32.0$ & \\
\hline Schizophrenia & $31(2.5)$ & $1033(83.0)$ & $180(14.5)$ & $\chi^{2}=34.7$ \\
\hline Unipolar depression & $36(4.5)$ & $670(84.4)$ & $88(11.1)$ & $\mathrm{p}<0.001$ \\
\hline Bipolar disorder & $4(1.2)$ & $267(77.8)$ & $72(21.0)$ & \\
\hline Bipolar depression & $3(1.2)$ & $195(75.3)$ & $61(23.5)$ & \\
\hline Bipolar mania & $1(1.2)$ & $72(85.7)$ & $11(13.1)$ & \\
\hline & & $\mathrm{MCHC}$ & & \\
\hline & $<32.0$ & $32.0-37.0$ & $>37.0$ & \\
\hline Schizophrenia & $18(1.4)$ & $1223(98.3)$ & $3(0.2)$ & $\chi^{2}=1.8$ \\
\hline Unipolar depression & $15(1.9)$ & $78(98.0)$ & $1(0.1)$ & $\mathrm{p}=0.94$ \\
\hline Bipolar disorder & $6(1.7)$ & $336(98.0)$ & $1(0.3)$ & \\
\hline Bipolar depression & $4(1.5)$ & $254(98.1)$ & $1(0.4)$ & \\
\hline Bipolar mania & $2(2.4)$ & $82(97.6)$ & 0 & \\
\hline & & RDW & & \\
\hline & $<11.6$ & $11.6-14.4$ & $>14.4$ & \\
\hline Schizophrenia & $3(0.2)$ & $1144(92.0)$ & $96(7.7)$ & $\chi^{2}=35.5$ \\
\hline Unipolar depression & $2(0.2)$ & $675(85.1)$ & $116(14.6)$ & $\mathrm{p}<0.001$ \\
\hline Bipolar disorder & $4(1.2)$ & $304(88.6)$ & $35(10.2)$ & \\
\hline Bipolar depression & $4(1.5)$ & $229(88.4)$ & $26(10.0)$ & \\
\hline Bipolar mania & 0 & $75(89.3)$ & $9(10.7)$ & \\
\hline
\end{tabular}

$\mathrm{RBC}=$ red blood cell count; $\mathrm{HCT}=$ hematocrit; $\mathrm{HGB}=$ hemoglobin; $\mathrm{MCV}=$ mean corpuscular volume;

$\mathrm{MCH}=$ mean corpuscular hemoglobin; $\mathrm{MCHC}=$ mean corpuscular hemoglobin concentration;

$\mathrm{RDW}=$ red blood cell distribution width. Results given as $\mathrm{n}(\%) ; \quad \chi^{2}=$ chi-squared test 
Table 5. Distribution of anemia and its subtypes in the study groups

\begin{tabular}{lcccccc} 
& Schizophrenia & $\begin{array}{c}\text { Unipolar } \\
\text { depression }\end{array}$ & $\begin{array}{c}\text { Group } \\
\text { Bipolar } \\
\text { disorder }\end{array}$ & $\begin{array}{c}\text { Bipolar } \\
\text { depression }\end{array}$ & Bipolar mania & Total \\
\hline $\begin{array}{l}\text { No anemia } \\
\begin{array}{l}\text { Anemia } \\
\text { macrocytic }\end{array}\end{array}$ & $1044(83.9)$ & $624(78.6)$ & $272(79.3)$ & $207(79.9)$ & $65(77.4)$ & $1940(81.5)$ \\
microcytic & $15(1.2)$ & $21(2.6)$ & $3(0.9)$ & $3(1.2)$ & 0 & $16(0.7)$ \\
normocytic & $179(14.4)$ & $142(17.9)$ & $68(19.8)$ & $49(18.9)$ & $19(22.6)$ & $389(16)$ \\
\hline
\end{tabular}

$\chi^{2}=24.5, \quad \mathrm{p}=0.004$ by overall Chi-square test. Results given as $\mathrm{n}(\%)$

Table 6. Correlations between hematological parameters and age in diagnostic groups

\begin{tabular}{lccccc}
\hline Parameter & & \multicolumn{3}{c}{ Group } \\
& Schizophrenia & Unipolar depression & Bipolar disorder & Bipolar depression & Bipolar mania \\
\hline RBC & $-0.39^{* * *}$ & $-0.32^{* * *}$ & $-0.24 * * *$ & $-0.23^{* * *}$ & $-0.49^{* * *}$ \\
HCT & $-0.35^{* * *}$ & $-0.15^{* * *}$ & $-0.23 * * *$ & $-0.18^{* *}$ & $-0.42^{* * *}$ \\
HGB & $-0.38^{* * *}$ & $-0.17^{* * *}$ & $-0.28^{* * *}$ & $-0.22^{* * *}$ & $-0.49 * * *$ \\
MCV & $0.14^{* * *}$ & $0.34^{* * *}$ & $0.11^{*}$ & $0.17 * *$ & 0.20 \\
MCH & 0.02 & $0.26^{* * *}$ & 0.00 & 0.05 & 0.01 \\
MCHC & $-0.23^{* * *}$ & $-0.07^{*}$ & $-0.20^{* * *}$ & $-0.18^{* *}$ & $-0.34^{* *}$ \\
RDW & $0.16^{* * *}$ & $0.15^{* * *}$ & $0.26^{* * *}$ & $0.13^{*}$ & $0.27^{*}$ \\
\hline
\end{tabular}

$\mathrm{RBC}=$ red blood cell count; $\mathrm{HCT}=$ hematocrit $\quad \mathrm{HGB}=$ hemoglobin; $\mathrm{MCV}=$ mean corpuscular volume;

$\mathrm{MCH}=$ mean corpuscular hemoglobin; $\mathrm{MCHC}=$ mean corpuscular hemoglobin concentration;

$\mathrm{RDW}=$ red blood cell distribution width. Results given as Spearman's correlation coefficient;

$* \mathrm{p}<0.05 ; * * \mathrm{p}<0.01 ; * * * \mathrm{p}<0.001$

and age was associated with increased risk $(\mathrm{OR}=1.04$ (95\% CI: 1.03-1.04), $\mathrm{p}<0.001)$. For MCV below normal value male sex was associated with decreased risk $(\mathrm{OR}=0.28$ (95\% CI: 0.14-0.55), $\mathrm{p}<0.001)$, while for MCV above normal value age was associated with increased risk (OR=1.04 (95\% CI: 1.01-1.06), $\mathrm{p}=0.001)$. For MCH below normal value male sex and age were associated with decreased risk $(\mathrm{OR}=0.18$ (95\% CI: $0.08-0.37), \mathrm{p}<0.001$ and $\mathrm{OR}=0.99 \quad(95 \% \mathrm{CI}: 0.98$ $0.99), \mathrm{p}=0.038$, respectively). For $\mathrm{MCH}$ above normal value diagnosis of bipolar depression $(\mathrm{OR}=1.58(95 \%$ CI: $1.12-2.21), \mathrm{p}=0.011)$, male sex $(\mathrm{OR}=1.47$ (95\% CI: $1.14-1.88), \mathrm{p}=0.002)$ and age $(\mathrm{OR}=1.02(95 \% \mathrm{CI}$ : 1.01-1.03), $\mathrm{p}<0.001)$ were associated with increased risk, while diagnosis of unipolar depression was associated with decreased risk $(\mathrm{OR}=0.63$ (95\% CI: 0.47 $0.85), \mathrm{p}=0.003)$. For MCHC below normal value male sex was associated with decreased risk $(\mathrm{OR}=0.08$ (95\% CI: 0.02-0.36), $\mathrm{p}=0.001$ ) and age was associated with increased risk (OR=1.02 (95\% CI: 1.00-1.04), $\mathrm{p}=0.025)$. No associations were found for MCHC above normal value. For RDW below normal value age was associated with decreased risk $(\mathrm{OR}=0.94$ (95\% CI: 0.89-0.98), $\mathrm{p}=0.007$ ) and diagnosis of bipolar depression was associated with increased risk $(\mathrm{OR}=7.93$ (95\% CI: 1.69-37.13), $\mathrm{p}=0.009)$. For RDW above normal value age and diagnosis of unipolar depression were associated with increased risk $(\mathrm{OR}=1.02(95 \%$ CI: $1.01-1.02), \mathrm{p}<0.001$ and $\mathrm{OR}=1.51$ (95\% CI: $1.11-$ 2.05), $\mathrm{p}=0.009$, respectively) and male sex was associated with reduced risk $(\mathrm{OR}=0.67$ (95\% CI: 0.49$0.91), \mathrm{p}=0.01)$.

\section{DISCUSSION}

The aim of this study was to investigate if there any differences in red blood cells parameters in a large sample $(n=2381)$ of patients with acute schizophrenia, unipolar depression, bipolar depression and bipolar mania. We have confirmed that there were differences for all analyzed parameters.

Patients with schizophrenia had the highest mean values of RBC, HCT, HGB and MCHC. Elevated hematocrit was previously described in patients with schizophrenia (Mathew \& Wilson 1987). Also, Hatta et al. found that patients in acute schizophrenia have increased risk of elevated hematocrit, probably due to dehydration secondary to acute psychosis (Hatta \& Takahashi et al. 1999). Also, in patients with schizophrenia the frequency of below normal values of RBC, HCT, $\mathrm{MCV}, \mathrm{MCHC}$ and RDW were lower compared with other clinical groups. Patients with schizophrenia had also the lowest prevalence of anemia (normo-, macroor microcytic). Previous studies show that patients with schizophrenia have lower erythrocyte deformability and enhanced aggregability (Riazantseva \& Novitskii 2002, Nakashima \& Ueda et al. 1996, Barshtein \& Ponizovsky et al. 2004), which may contribute to increased risk of cardiovascular disorders associated with schizophrenia.

Patients with unipolar depression had the highest mean value of RDW and the lowest mean values of $\mathrm{HCT}, \mathrm{HGB}, \mathrm{MCV}, \mathrm{MCH}$ and MCHC. Also, in this group the highest frequency of below normal values of $\mathrm{HCT}$, HGB, MCV, MCH, MCHC was observed. Moreover, patients with unipolar depression had the 
highest prevalence of all three subtypes of anemia. This observation is consistent with previous studies, which showed the relationship between major depression and decreased red blood cell parameters (Maes \& Van de Vyvere 1996, Alves de Rezende \& Coelho 2009). Low values of red blood cells parameters may also contribute to the risk of developing depression, e.g. low hemoglobin level is considered as one of the risk factors for postpartum depression (Corwin \& Murray-Kolb et al. 2003). One of the hypotheses explaining why patients with depression have worse red blood cells suggests that during major depression immune-inflammatory response may induce disorders in iron metabolism and the erythron (Maes \& Van de Vyvere 1996). However, we have previously found there are no differences in Creactive protein levels (which is a sensitive indicator of inflammatory conditions) between patients with schizophrenia, unipolar depression and bipolar disorder (Wysokinski \& Margulska et al. 2015), which may indicate there are no inflammatory differences between these conditions. Therefore, this cannot explain observed differences in red blood cells parameters. Observed higher values of RDW in patients with depression may have important clinical consequences, since higher RDW is associated with elevated risk of stroke, independent of anaemia and traditional atherosclerotic risk factors (Lappegard \& Ellingsen et al. 2016).

Patients with bipolar disorder had the highest values of $\mathrm{MCV}$ and $\mathrm{MCH}$, also the lowest mean value of $\mathrm{RBC}$ was found in these patients. The highest frequency of below normal value of RBC was found in patients with bipolar disorder. Interestingly, we have not confirmed previous observation that there are differences in hematological parameters depending on the type of bipolar disorder episode. Hochman et al. found that patients during depressive episode have higher levels of HGB and HCT and lower levels of HGB and HCT during maniac episodes (Hochman \& Weizman et al. 2014).

For the majority of parameters, male sex was associated with decreased risk of below normal values, while age was associated with elevated risk. As shown in larger epidemiological studies, men have higher values of most red blood cells parameters (Troussard \& Vol et al. 2014). Also, across all clinical groups, age was negatively correlated with the majority of parameters. In the study group there were more men in the schizophrenia group. Also, patients with schizophrenia were significantly younger. These two discrepancies may result in observed better hematological parameters in patients with schizophrenia.

Our study has some limitations, which result from its cross-sectional and naturalistic design, as well as lack of control group. The major limitation is the lack of adequate controls (healthy subjects). We only have data representing current red blood cells parameters and have no information regarding past hematological abnormalities. Red blood cells parameters may also result from other factors, which could not be included in the analysis, such as chronic comorbidities, medications used by patients (e.g. nonsteroidal anti-inflammatory drugs, iron or other), details of psychiatric treatment (e.g. electroconvulsive therapy may affect hemoglobin concentration (Chaturvedi \& Chadda et al. 2001)), smoking (Flouris \& Poulianiti et al. 2012), metabolic parameters, such as body mass index or waist circumference (Vuong \& Qiu et al. 2014), duration of disease, etc. Diagnostic groups were not homogenous, there were less women in the schizophrenia group comparing to other groups, while patients with unipolar and bipolar depression were significantly older comparing to other groups. Also, the bipolar disorder group was smaller comparing to schizophrenia and unipolar disorder (this is particularly true for bipolar mania group). These factors may affect results of intra- and inter-group comparisons. On the other hand, naturalistic design, large sample size and ability to compare tree major clinical groups (schizophrenia, unipolar disorder and bipolar disorder) are major strengths of the study. Also, there are no studies comparing differences in red blood cells parameters between these diagnostic groups.

\section{CONCLUSION}

Our study showed that there are differences in red cells parameters between schizophrenia, unipolar depression and bipolar disorder (both in manic and depressive episode). We have found that compared with schizophrenia, significantly higher percentage of patients with unipolar- or bipolar affective disorders has anemia or abnormal red cells parameters. Positive correlations between age and MCV and RDW and negative correlations between age and other parameters were found in all study groups. Since many psychiatric patients are at increased risk of cardiovascular disorders due to many risk factors (such as atherosclerosis, obesity or smoking), monitoring for abnormal red cells status is recommended.

\section{Acknowledgements: None.}

Conflict of interest: None to declare.

\section{Contribution of individual authors:}

Adam Wysokiński: study design, literature review, statistical analyses, manuscript preparation, approval of the final version;

Ewa Szczepocka: study design, literature review, data collection, statistical analyses, manuscript preparation, approval of the final version.

\section{References}

1. Alves de Rezende CH, Coelho LM, Oliveira LM, Penha Silva N: Dependence of the geriatric depression scores on age, nutritional status, and haematologic variables in elderly institutionalized patients. J Nutr Health Aging 2009; 13:617-21 
2. Barshtein G, Ponizovsky AM, Nechamkin Y, Ritsner M, Yedgar S, Bergelson LD: Aggregability of red blood cells of schizophrenia patients with negative syndrome is selectively enhanced. Schizophr Bull 2004; 30:913-22

3. Beutler E, Waalen J: The definition of anemia: what is the lower limit of normal of the blood hemoglobin concentration? Blood 2006; 107:1747-50

4. Chaturvedi S, Chadda RK, Rusia U, Jain N: Effect of electroconvulsive therapy on hematological parameters. Psychiatry Res 2001; 104:265-8

5. Corwin EJ, Murray-Kolb LE, Beard JL: Low hemoglobin level is a risk factor for postpartum depression. J Nutr 2003; 133:4139-42

6. Ellman LM, Vinogradov S, Kremen WS, Poole JH, Kern $D M$, Deicken RF et al.: Low maternal hemoglobin during pregnancy and diminished neuromotor and neurocognitive performance in offspring with schizophrenia. Schizophr Res 2012; 138:81-7

7. Flouris AD, Poulianiti KP, Chorti MS, Jamurtas AZ, Kouretas D, Owolabi EO et al.: Acute effects of electronic and tobacco cigarette smoking on complete blood count. Food Chem Toxicol 2012; 50:3600-3

8. George-Gay B, Parker K: Understanding the complete blood count with differential. J Perianesth Nurs 2003; 18:96-114; quiz 5-7

9. Hatta $K$, Takahashi T, Nakamura H, Yamashiro $H$, Matszaki I, Asukai $N$ et al.: Laboratory findings in acute schizophrenia. Relevance to medical management on emergency admission. Gen Hosp Psychiatry 1999; 21:220-7

10. Hochman E, Weizman A, Valevski A, Fischel T, Krivoy A: Association between bipolar episodes and fluid and electrolyte homeostasis: a retrospective longitudinal study. Bipolar Disord 2014; 16:781-9

11. Lappegard J, Ellingsen TS, Skjelbakken T, Mathiesen EB, Njolstad I, Wilsgaard T et al.: Red cell distribution width is associated with future risk of incident stroke. The Tromso Study. Thromb Haemost 2016; 115:126-34

12. Maes M, Van de Vyvere J, Vandoolaeghe E, Bril T, Demedts $P$, Wauters A et al.: Alterations in iron metabolism and the erythron in major depression: further evidence for a chronic inflammatory process. J Affect Disord 1996; 40:23-33

13. Mathew RJ, Wilson WH: Elevated hematocrit in patients with schizophrenia. Biol Psychiatry 1987; 22:907-10

14. Nakashima H, Ueda K, Yasugawa S, Katsuragi S, Kimura T, Miyakawa T: Erythrocyte deformability in schizophrenic patients. Psychiatry Clin Neurosci 1996; 50:191-4

15. Riazantseva NV, Novitskii VV: [Structural and metabolic status and functional properties of erythrocytes in schizophrenic patients]. Zh Nevrol Psikhiatr Im $S$ S Korsakova 2002; 102:36-42

16. Troussard X, Vol S, Cornet E, Bardet V, Couaillac JP, Fossat $C$ et al.: Full blood count normal reference values for adults in France. J Clin Pathol 2014; 67:341-4

17. Vuong J, Qiu Y, La M, Clarke G, Swinkels DW, Cembrowski G: Reference intervals of complete blood count constituents are highly correlated to waist circumference: should obese patients have their own "normal values?". Am J Hematol 2014; 89:671-7

18. Wysokinski A, Margulska A, Strzelecki D, Kloszewska I: Levels of C-reactive protein (CRP) in patients with schizophrenia, unipolar depression and bipolar disorder. Nord J Psychiatry 2015; 69:346-53

Correspondence:

Adam Wysokiński, MD, PhD

Department of Old Age Psychiatry and Psychotic Disorders, Medical University of Lodz Czechoslowacka 8/10, 92-216 Łódź, Poland

E-mail: adam.wysokinski@umed.lodz.pl 